\title{
Kesetaraan Gender dan Strategi Nafkah untuk Penyusunan Program Penyuluhan pada Masyarakat Pesisir di Kabupaten Tanggamus, Provinsi Lampung
}

\section{Gender Equality and Livelihood Strategies for Outreach Programs in Coastal Communities at Tanggamus Regency, Lampung Province}

\author{
Helvi Yanfika ${ }^{1, *)}$, Begem Viantimala ${ }^{1}$, Indah Nurmayasari ${ }^{1}$, Abdul Mutolib $^{2}$
}

${ }^{1}$ Program Studi Penyuluhan Pertanian, Universitas Lampung, Bandar Lampung 35141, Indonesia

${ }^{2}$ Program Magister Agribisnis, Program Pascasarjana Universitas Siliwangi, Kota Tasikmalaya 46155, Indonesia

${ }^{*}$ E-mail korespondensi: helviyanfika@yahoo.co.id

Diterima: 29 November 2020 | Disetujui: 5 Juli 2021 | Publikasi Online: 12 Juli 2021

\begin{abstract}
This study aims to determine multiple livelihood strategies and collaboration for livelihood strategies and preparation of extension programs in the perspective of gender equality in fishing communities. The research method uses quantitative and qualitative approaches. The data were analyzed descriptively and statistically The research location is in Limau District Tanggamus Regency and the number of respondents was 80 fishermen. The data used are primary and secondary data. The results of this study indicate that the community applies a dual livelihood strategy and a collaborative livelihood strategy in Limau District consisting of On Farm strategy, On-Farm and Off-Farm, and On-Farm and Non-Farm. Cumulatively, the gender relations of fishermen's families in Limau District covering domestic, public and community activities have shown an equal division of labor between wives and husbands, namely 76.30 percent. Extension programs should aim at gender equality so as to increase their participation, access and control, as well as the benefits that women enjoy in developing coastal areas. Thus, the results of marine and fisheries development can touch all levels of society and bring society to prosperity and a better life.
\end{abstract}

Keywords : Extension program, fisherman, gender, income, livelihood strategy

\section{ABSTRAK}

Penelitian ini bertujuan untuk mengetahui strategi nafkah ganda, kolaborasi strategi nafkah, serta penyusunan program penyuluhan dalam perspektif kesetaraan gender pada masyarakat nelayan. Metode penelitian menggunakan pendekatan kuantitatif dan kualitatif. Data dianalisis secara deskriptif dan statistik. Lokasi penelitian di Kecamatan Limau Kabupaten Tanggamus dengan responden sebanyak 80 nelayan. Data yang digunakan adalah data primer dan sekunder. Hasil Penelitian ini menunjukkan bahwa masyarakat menerapkan strategi nafkah ganda dan kolaborasi strategi nafkah yang terdiri atas On Farm, On-Farm dan Off-Farm, serta strategi On-Farm dan Non-Farm. Secara akumulatif relasi gender keluarga nelayan di Kecamatan Limau mencakup kegiatan domestik, publik, dan kemasyarakatan telah menunjukkan adanya kesetaraan pembagian kerja antara istri dan suami yaitu sebesar 76,30 persen. Program penyuluhan hendaknya mengarah pada kesetaraan gender sehingga dapat meningkatkan partisipasi, akses, dan kontrol yang dimiliki, serta manfaat yang dinikmati perempuan dalam pembangunan wilayah pesisir. Dengan demikian, hasil pembangunan kelautan dan perikanan dapat menyentuh seluruh lapisan masyarakat dan membawa masyarakat kepada kesejahteraan serta kehidupan yang lebih baik.

Kata kunci: Program penyuluhan, nelayan, gender, pendapatan, strategi nafkah

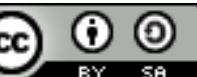

Content from this work may be used under the terms of the Creative Commons Attribution-ShareAlike 4.0 International. Any further distribution of this work must maintain attribution to the author(s) and the title of the work, journal citation and DOI.

Published under Department of Communication and Community Development Science, IPB University and in association with Perhimpunan Ahli Penyuluhan Pembangunan Indonesia.

E-ISSN: 2442-4110 | P-ISSN: 1858-2664 


\section{PENDAHULUAN}

Sektor kelautan merupakan salah satu sektor andalan di Indonesia (Ridwan et al., 2019). Provinsi Lampung memiliki potensi sumberdaya perikanan yang melimpah dan menjadi tumpuan masyarakat. (Syetiawan, 2015; Delly et al., 2019). Salah satu wilayah di Provinsi Lampung yang menjadi sentra perikanan tangkap adalah Kabupaten Tanggamus. Sentra perikanan tangkap Kabupaten Tanggamus terletak di Kecamatan Limau (Yanfika et al., 2019). Sebagian besar penduduk di Kecamatan Limau bermatapencaharian sebagai nelayan. Nelayan di Kecamatan Limau terkonsentrasi di wilayah pesisir pantai Teluk Semangka (Yanfika et al., 2020).

Pemanfaatan sektor kelautan dilakukan melalui modernisasi perikanan tangkap (Munafi \& Tenri, 2016; Imelda et al., 2019). Hal ini dilakukan untuk meningkatkan kesejahteraan nelayan serta dapat mendukung kemajuan suatu daerah (Schoorl, 1984). Modernisasi perikanan tangkap dilakukan dengan penggunaan mesin motor (motorisasi) dan alat tangkap yang modern dan berteknologi tinggi (Nur \& Najamuddin, 2020). Meskipun demikian, kemajuan peralatan perikanan tangkap masih belum mampu mendukung kemajuan sektor kelautan sebagai sektor andalan untuk meningkatkan taraf hidup nelayan (Yuliana et al., 2016; Hamzah et al., 2019). Pendapatan nelayan yang relatif rendah membuat nelayan tidak bisa bergantung dari pekerjaan disektor kelautan (Damayanti, 2018). Hal ini dikarenakan hasil tangkapan yang tidak bisa dipastikan akibat keadaan cuaca yang tidak menentu. Keadaan tersebut akan berpengaruh terhadap taraf hidup nelayan.

Pada tingkat rumah tangga nelayan, strategi nafkah dapat bermanfaat dalam mengatur sumberdaya ekonomi nelayan (Anggraini, 2018). Strategi nafkah adalah suatu kondisi rumah tangga dalam upaya mengembangkan atau membangun kapasitas diri baik individu dan kelompok sosial untuk peningkatan kualitas taraf hidup dan bertahan dari berbagai kondisi yang tidak pasti (Widodo, 2011). Nelayan umumnya menerapkan beberapa jenis pola strategi nafkah diantaranya nafkah ganda, ekstensifikasi, intensifikasi, migrasi serta stradding strategy (Malik et al., 2018; Pattiselanno et al., 2018; Fridayanti \& Dharmawan, 2015). Strategi nafkah nelayan sangat berhubungan erat dengan manajemen keuangan dalam rumah tangga nelayan itu sendiri serta kualitas hidup nelayan. Manajemen keuangan merupakan suatu kegiatan perencanaan, penganggaran, pemeriksaan, pengelolaan, pengendalian, pencarian, dan penyimpanan dana yang dalam hal ini dilakukan oleh rumah tangga nelayan. Kegiatan masyarakat pesisir cenderung bersifat patriarki dan memandang kaum perempuan pada posisi kedua setelah lakilaki (Sakina \& Siti, 2017; Nimrah et al., 2015). Budaya patriarki pada masyarakat pesisir menyebabkan terjadinya bias gender dalam masyarakat termasuk dalam dunia pertanian secara luas (Istiana, 2014).

Ketidaksetaraan gender dalam bidang pertanian dan kelautan disebabkan oleh akses perempuan yang terbatas dalam pengambilan keputusan dan terhadap sumberdaya ekonomi (Yuliani, 2014). Hal tersebut pada akhirnya berkontribusi terhadap kesenjangan laki-laki dan perempuan dalam berbagai bidang khsusunya dalam sektor perikanan (Hutajulu, 2014; Fauziyah, 2018). Selain strategi nafkah, dalam kegiatan pengembangan masyarakat pesisir seperti kegiatan penyuluhan juga, masih banyak sekali dominasi kaum laki-laki. Kaum perempuan pada kegiatan penyuluhan di pesisir seringkali menjadi pihak kedua yang tidak memperoleh akses terhadap informasi, akses, dan pelatihan yang cukup. Oleh karena itu, penting sekali pengembangan penyuluhan pada masyarakat pesisir dan nelayan yang responsif gender agar perempuan di pesisir memiliki akses yang luas dan setara dengan kaum pria. Penelitian ini bertujuan untuk mengkaji terkait bagaimana strategi nafkah ganda dan kolaborasi strategi nafkah serta penyusunan program penyuluhan dalam perspektif kesetaraan gender pada masyarakat pesisir di Kabupaten Tanggamus. 


\section{METODE PENELITIAN}

\section{Lokasi dan Waktu Penelitian}

Penelitian dilaksanakan pada bulan Juli hingga Agustus 2020. Lokasi penelitian terletak di Kabupaten Taggamus Provinsi Lamapung dengan lokasi spesifik di Kecamatan Limau. Kecamatan Limau dipilih menjadi lokasi penelitian dengan pertimbangan terletak di pesisir Teluk Semangka dan sentra perikanan tangkap laut di Kabupaten Tanggamus.

\section{Jenis Data dan Pendekatan Penelitian}

Penelitian menggunakan data sekunder dan primer. Data primer diperoleh dari sumber atau responden secara langsung dengan metode wawancara (interview). Selain data primer, penelitian ini juga menggunakan data sekunder yang diperoleh dari berbagai sumber referensi seperti jurnal, buku, laporan dan lainnya. Penelitian menggunakan pendekatan kuantitatif dengan metode survei (survey) dengan jumlah responden sebanyak 80 nelayan di Kecamatan Limau. Secara garis besar penelitian ini terdiri dari tiga tahapan yaitu tahap invention yang terdiri dari tahap pra-lapangan yang terdiri dari menyusun instrumen penelitian, penentuan lokasi penelitian, dan menentuan responden atau informan penelitian. Tahap selanjutnya discovery yang meliputi pengambilan data penelitian, dan tahapan ketiga adalah explanation yang meliputi tiga kegiatan yaitu pengolahan dan mendeskripsikan data yang telah dikumpulkan (Creswell, 2014; Huberman \& Miles, 2012).

\section{Analisis Data}

Analisis data menggunakan metode tabulasi silang atau Crosstabs untuk menganalisis frekuensi dan persentase dua atau lebih variabel secara sekaligus dengan cara menyilangkan variabel-variabel yang dianggap berhubungan. Hal tersebut dilakukan agar makna dari hubungan kedua variabel tersebut dapat mudah dipahami secara deskriptif (Ashari et al., 2017). Analisis gender didekati dengan analisis Harvard serta path analysis.

\section{HASIL DAN PEMBAHASAN}

\section{Karakteristik Responden}

Tabel 1. Karakteristik responden menurut kategori umur

\begin{tabular}{cccc}
\hline & Umur (Tahun) & Jumlah (Jiwa) & Presentase $(\%)$ \\
\hline & $20-40$ & 46 & 57,50 \\
& $41-60$ & 28 & 35 \\
& $61-80$ & 6 & 7,50 \\
\hline Total & & $\mathbf{8 0}$ & $\mathbf{1 0 0}$ \\
\hline
\end{tabular}

Sumber: Data Primer, 2020.

Umumnya responden mulai pergi melaut sejak umur 20 tahun. Pada umur 20 tahun pemuda telah memiliki rasa tanggung jawab terhadap keberlangsungan ekonomi dan kebutuhan nafkah keluarga. Mayoritas nelayan di Kecamatan Limau berada pada umur produktif yaitu dengan rentang umur 20 tahun sampai 40 tahun atau sebesar 57,50 persen. Sementara, pada rentang umur 61 tahun sampai 80 tahun berjumlah 37 persen. Nelayan pada rentang umur ini hanya sebesar 7,50 persen. Hal ini dikarenakan pengaruh umur yang sudah cenderung tidak produktif sehingga rata-rata nelayan yang berada pada rentang umur ini hanya bekerja pada saat tertentu saja dan lebih memilih menyerahkan tugas tersebut kepada anak dan cucu mereka yang dianggap lebih muda dan lebih mampu. 
Tabel 2. Karateristik responden menurut kategori pendidikan

\begin{tabular}{|c|c|c|}
\hline Pendidikan & Jumlah (Jiwa) & Presentase (\%) \\
\hline SD & 43 & 53,75 \\
\hline SMP & 21 & 26,25 \\
\hline SMA & 14 & 17,50 \\
\hline Tidak tamat SD & 1 & 1,25 \\
\hline Tidak sekolah & 1 & 1,25 \\
\hline Total & 80 & 100 \\
\hline
\end{tabular}

Sumber: Data Primer, 2020

Mayoritas responden memiliki tingkat pendidikan hingga tamat Sekolah Dasar (SD) dengan persentase sebesar 53,75 persen. Masyarakat yang menyelesikan pendidikan tingkat Sekolah Menengah Pertama (SMP) hanya 26,25 persen, dan sebanyak 17,50 persen nelayan yang menyelesaikan pendidikan Sekolah Menegah Atas (SMA). Salah satu faktor yang menyebabkan rendahnya pendidikan nelayan di Kecamatan Limau adalah rendahnya ekonomi dan warisan pekerjaan sebagai nelayan yang dirasa menghambat pendidikan bagi para remaja di wilayah pesisir Kecamatan Limau.

Tabel 3. Karateristik responden menurut kategori jenis kelamin

\begin{tabular}{lccc}
\hline & Jenis Kelamin & Jumlah & Presentase (\%) \\
\hline Laki-laki & 62 & 77,50 \\
Perempuan & 18 & 22,50 \\
\hline Total & $\mathbf{8 0}$ & $\mathbf{1 0 0}$ \\
\hline
\end{tabular}

Sumber: Data Primer, 2020.

Pengambilan sampel dilakukan secara random sampling dengan menggunakan tabel acak sehingga didapatkan jumlah responden sebanyak 80 nelayan yang terdiri dari 62 nelayan berjenis kelamin lakilaki (77,50 persen) dan 18 nelayan berjenis kelamin perempuan (22,50 persen).

Tabel 4. Karakteristik responden menurut kategori pendapatan

\begin{tabular}{lcc}
\hline Pendapatan (Rp/bulan) & Jumlah & Presentase (\%) \\
\hline$<2.432 .000$ & 18 & 22,50 \\
$>2.432 .000$ & 62 & 77,50 \\
\hline Total & $\mathbf{8 0}$ & $\mathbf{1 0 0}$ \\
\hline
\end{tabular}

Sumber: Data Primer, 2020

Dalam aspek pendapat rumah tangga, sebanyak 18 rumah tangga atau 22,50 persen memiliki pendapatan kurang dari Rp. 2.432 .000 perbulan dan sebanyak 62 responden atau 77,50 persen memiliki pendapatan rumah tangga diatas Rp. 2.432 .000 perbulan.

\section{Gender dan Strategi Penghidupan Nelayan}

\section{Relasi Gender Keluarga Nelayan}

Relasi gender difokuskan pada peran yang dilakukan laki laki dan perempuan dalam melakukan strategi penghidupan nelayan baik pada kegiatan domestik, publik, dan kemasyarakatan. Pembagian peran di Kecamatan Limau terbagi dalam tiga kategori yaitu dilakukan suami, dilakukan istri, dan setara. Relasi gender keluarga nelayan di Kecamatan Limau terdiri atas kegiatan domestik, publik/produktif, dan kemasyarakatan. Kegiatan domestik dominan dilakukan oleh istri. Kegiatan domestik ini mencakup kegiatan-kegiatan yang dilakukan setiap hari dalam rumah tangga seperti mencuci piring, belanja bahan makanan, merencanakan perbaikan rumah, memperbaiki rumah ketika rusak, membayar tagihan listrik/air, mencuci baju, mengasuh anak (menjaga, bermain), merencanakan pendidikan anak, membayar biaya sekolah anak, mencari informasi tentang tumbuh kembang anak, merawat anak ketika 
sakit, memasak makanan, mengatur menu makanan, membersihkan rumah (menyapu dan mengepel), menyetrika pakaian, merencanakan keuangan keluarga, mengatur keuangan keluarga, menata ruangan, membayar biaya asuransi kesehatan, dan belanja peralatan rumah tangga.

Tabel 5. Relasi Gender Keluarga Nelayan

\begin{tabular}{|c|c|c|c|c|}
\hline Kegiatan & $\begin{array}{l}\text { Istri } \\
(\%)\end{array}$ & $\begin{array}{c}\text { Setara } \\
(\%)\end{array}$ & $\begin{array}{c}\text { Suami } \\
(\%)\end{array}$ & $\begin{array}{c}\text { Total } \\
(\%)\end{array}$ \\
\hline \multicolumn{5}{|l|}{ Domestik } \\
\hline Mencuci piring & 87,50 & 0,00 & 12,50 & 100 \\
\hline Belanja bahan makanan & 92,50 & 0,00 & 7,50 & 100 \\
\hline Merencanakan perbaikan rumah & 25,00 & 46,25 & 28,75 & 100 \\
\hline Memperbaiki rumah ketika rusak & 6,25 & 86,25 & 7,50 & 100 \\
\hline Membayar tagihan listrik/air & 31,25 & 42,50 & 26,25 & 100 \\
\hline Mencuci baju & 95,00 & 1,25 & 3,75 & 100 \\
\hline Mengasuh anak (menjaga, bermain) & 68,75 & 0,00 & 31,25 & 100 \\
\hline Merencanakan pendidikan anak & 48,75 & 1,25 & 50,00 & 100 \\
\hline Membayar biaya sekolah anak & 31,25 & 46,25 & 22,50 & 100 \\
\hline Mencari informasi tentang tumbuh kembang anak & 80,00 & 0,00 & 20,00 & 100 \\
\hline Merawat anak ketika sakit & 61,25 & 0,00 & 38,75 & 100 \\
\hline Memasak makanan & 93,75 & 1,25 & 5,00 & 100 \\
\hline Mengatur menu makanan & 87,50 & 5,00 & 7,50 & 100 \\
\hline Membersihkan rumah (menyapu dan mengepel) & 86,25 & 0,00 & 13,75 & 100 \\
\hline Menyetrika pakaian & 97,50 & 0,00 & 2,50 & 100 \\
\hline Merencanakan keuangan keluarga & 68,75 & 7,50 & 23,75 & 100 \\
\hline Mengatur keuangan keluarga & 78,75 & 6,25 & 15,00 & 100 \\
\hline Menata ruangan & 72,50 & 11,25 & 16,25 & 100 \\
\hline Membayar biaya asuransi kesehatan & 25,00 & 53,75 & 21,25 & 100 \\
\hline Belanja peralatan rumah tangga & 76,25 & 3,75 & 20,00 & 100 \\
\hline \multicolumn{5}{|l|}{ Publik/Produktif } \\
\hline Bekerja mencari nafkah lebih dari 40 jam per minggu & 96,25 & 0,00 & 3,75 & 100 \\
\hline $\begin{array}{l}\text { Mencari informasi kerja untuk menambah } \\
\text { pendapatan keluarga }\end{array}$ & 0,00 & 88,75 & 11,25 & 100 \\
\hline Mencari informasi kursus pengembangan & 1,25 & 86,25 & 12,50 & 100 \\
\hline keterampilan untuk menambah pendapatan keluarga & & & & \\
\hline Menambah jam kerja & 0,00 & 96,25 & 3,75 & 100 \\
\hline Memiliki pekerjaan lain/musiman & 3,75 & 85,00 & 11,25 & \\
\hline \multicolumn{5}{|l|}{ Kemasyarakatan } \\
\hline Mengikuti pertemuan RT/RW & 1,25 & 93,75 & 5,00 & 100 \\
\hline $\begin{array}{l}\text { Tolong menolong dengan keluarga besar dan } \\
\text { tetangga }\end{array}$ & 0,00 & 7,50 & 92,5 & 100 \\
\hline Partisipasi dalam kegiatan masyarakat & 0,00 & 26,25 & 73,75 & 100 \\
\hline Mengikuti arisan & 4,50 & 40,00 & 12,50 & 100 \\
\hline Mengikuti organisasi sosial & 1,25 & 3,75 & 95 & 100 \\
\hline Mengikuti kegiatan agama & 2,50 & 93,75 & 3,75 & 100 \\
\hline Rata-rata & 44,55 & 31,75 & $\mathbf{7 6 , 3 0}$ & 100 \\
\hline
\end{tabular}

Sumber: Data Primer, 2020

Kegiatan publik dan kemasyarakatan dominan dilakukan oleh suami. Kegiatan publik tersebut mencakup beberapa hal, antara lain bekerja mencari nafkah lebih dari 40 jam per minggu, mencari informasi kerja untuk menambah pendapatan keluarga, mencari informasi kursus pengembangan keterampilan untuk menambah pendapatan keluarga, menambah jam kerja, dan memiliki pekerjaan lain/musiman. Untuk kegiatan kemasyarakatan sendiri mencakup beberapa hal antara lain gotong royong/kerja bakti di lingkungan rumah, mengikuti pertemuan RT/RW, tolong menolong dengan keluarga besar dan tetangga, partisipasi dalam kegiatan masyarakat, mengikuti arisan, mengikuti 
organisasi sosial, mengikuti kegiatan agama.

Diketahui bahwa secara akumulatif relasi gender keluarga nelayan yang mencakup kegiatan domestik, publik, dan kemasyarakatan telah menunjukkan adanya kesetaraan pembagian kerja antara istri dan suami. Sebesar 76,30 persen pekerjaan dilakukan oleh suami. Sebesar 44,55 persen pekerjaan dilakukan oleh istri, dan 31,75 persen pekerjaan dilakukan secara bersama. Hal ini menunjukkan bahwa secara akumulatif relasi gender dalam keluarga nelayan telah bersifat responsif gender yaitu dengan melakukan kegiatan secara bersama-sama baik suami maupun istri tanpa adanya dominansi pada salah satu pihak.

\section{Pengaruh Relasi Gender, Manajemen Keuangan dan Kualitas Hidup terhadap Pendapatan Keluarga Petani dan Nelayan secara Simultan}

Besarnya pengaruh relasi gender, manajemen keuangan, dan kualitas hidup secara simultan terhadap pendapatan keluarga nelayan terlihat dari nilai Rsquare $\left(\mathrm{R}^{2}\right)$ yang diperoleh yaitu sebesar 12.10 persen sedangkan sisanya yaitu sebesar 87.90 persen dipengaruhi oleh faktor lain yang tidak diteliti dalam penelitian ini. Secara rinci, berikut hasil perhitungan analisis pengaruh relasi gender, manajemen keuangan, dan kualitas hidup secara simultan terhadap pendapatan keluarga petani dan nelayan yang disajikan pada Tabel 6.

Tabel 6. Relasi gender, manajemen keuangan, dan kualitas hidup secara simultan terhadap pendapatan nelayan

\begin{tabular}{cccc}
\hline R square $\left(\mathbf{R}^{2}\right)$ & F hitung & F table & Sig \\
\hline 0.121 & 3.498 & 3.115 & 0.019 \\
\hline
\end{tabular}

Hasil analisis juga menunjukkan bahwa f hitung (3.498) > f tabel (3.115), artinya relasi gender, manajemen keuangan, dan kualitas hidup secara simultan berpengaruh signifikan terhadap pendapatan keluarga nelayan dan petani. Selain itu, berdasarkan hasil analisis juga diperoleh nilai signifikansi yaitu $0.019<0.05$, artinya pengujian secara individual dari masing-masing variabel tersebut dapat dilakukan.

\section{Pengaruh Relasi Gender, Manajemen Keuangan, dan Kualitas Hidup terhadap Pendapatan Keluarga Petani dan Nelayan}

Variabel kualitas hidup memiliki nilai signifikansi sebesar $0.002<0.05$ dan nilai t hitung sebesar 3.206 $>$ nilai t tabel yaitu 1.991. Hal tersebut berarti bahwa kualitas hidup memiliki pengaruh terhadap pendapatan keluarga nelayan. Hasil analisis juga menunjukkan bahwa nilai signifikansi relasi gender dan manajemen keuangan secara berurutan sebesar 0.520 dan $0.846>0.05$ dan nilai t tabel sebesar 0.647 dan $0.194<$ nilai $t$ tabel (1.991). Artinya, relasi gender dan manajemen keuangan tidak memiliki pengaruh terhadap pendapatan keluarga petani dan nelayan. Hasil analisis jalur ditampilkan pada Tabel 7.

Tabel 7. Hasil analisis pengaruh relasi gender, manajemen keuangan, kualitas hidup terhadap pendapatan nelayan

\begin{tabular}{lcccccc}
\hline Variabel/Sub Variabel & B & Std. Error & Beta & t hitung & t tabel & Sig \\
\hline Relasi Gender & -22052.140 & 34085.674 & -0.073 & -0.647 & 1.991 & 0.520 \\
Manajemen Keuangan & 8790.031 & 45197.049 & 0.022 & 0.194 & 1.991 & 0.846 \\
Kualitas Hidup & 88008.804 & 27452.339 & 0.347 & 3.206 & 1.991 & 0.002 \\
\hline
\end{tabular}

Nilai $\mathrm{R}^{2}$ sebesar 0.347 artinya kualitas hidup mempengaruhi sebesar $34.7 \%$ terhadap pendapatan keluarga nelayan dan sisanya yaitu sebesar $65.3 \%$ dipengaruhi oleh faktor lain yang tidak diteliti pada penelitian ini. Berikut ini gambar diagram jalur penelitin ini yang tersaji pada Gambar 1. 


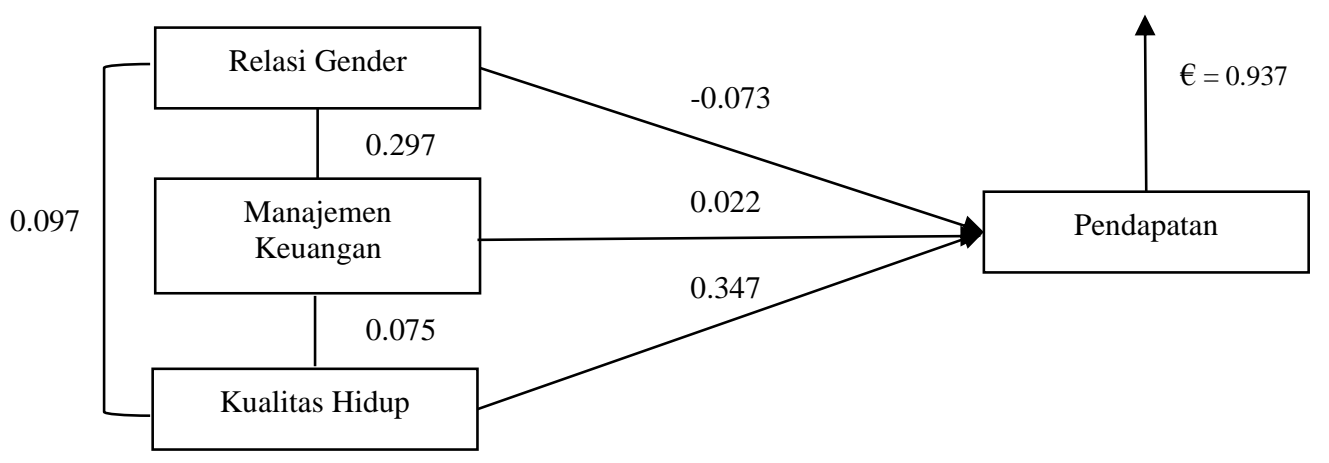

Gambar 1. Diagram Alur Kesetaraan Gender dan Strategi Nafkah Rumah Tangga Nelayan

\section{Strategi dan Rekayasa Nafkah Nelayan}

Pembentuk strategi nafkah terdiri atas tiga hal diantaranya yaitu On-Farm, Off-Farm dan Non Farm (Sembiring \& Dharmawana, 2015; Salatalohy, 2019). Strategi nafkah masyarakat nelayan di Kecamatan Limau terdiri dari kombinasi On-Farm, On farm-off farm dan On farm-non farm. Strategi On-Farm bersumber dari hasil tangkapan ikan (melaut) dan hasil pertanian yang didominasi tanaman keras seperti cengkeh, duku dan kakao. Strategi nafkah On-Farm dan Off-Farm berasal dari hasil tangkapan ikan laut dan jasa/untung dari pengolahan ikan. Strategi yang ketiga yaitu On-Farm dan Non-Farm yang berasal dari hasil tangkapan ikan serta upah dari pekerjaan lain diluar sektor perikanan seperti buruh, supir, pedagang dan lainnya. Kolaborasi strategi nafkah nelayan di Kecamatan Limau yang disajikan pada Tabel 8.

Tabel 8. Strategi nafkah nelayan di Kecamatan Limau

\begin{tabular}{lcc}
\hline \multicolumn{1}{c}{ Kolaborasi strategi nafkah } & Jumlah & Presentase (\%) \\
\hline On farm & 47 & 58,75 \\
On farm-off farm & 11 & 13,75 \\
On farm-non farm & 22 & 27,5 \\
\hline Total & $\mathbf{8 0}$ & $\mathbf{1 0 0}$ \\
\hline
\end{tabular}

Sumber: Data Primer, 2020

Strategi nafkah yang paling dominan pada masyarakat nelayan di Limau adalah strategi nafkah OnFarm. Masyarakat menilai bahwa strategi ini cukup efektif karena apabila hasil tangkapan ikan menurun maka para nelayan akan beralih ke hasil pertanian di darat. Strategi nafkah yang digunakan oleh sebagian kecil nelayan adalah kolaborasi On-Farm dan Non Farm atau kolaborasi yang berasal dari hasil pertanian dan luar pertanian seperti buruh, supir, kuli bangunan, pedagang, dan sebagainya. Perempuan memiliki peranan sangat penting dalam membantu mencari nafkah untuk mencukupi kebutuhan keluarga (Mutolib et al., 2016; Nurmayasari et al., 2020). Umumnya banyak nelayan melakukan strategi nafkah kolaborasi antara sektor perikanan (nelayan) dan pertanian (petani) (Pattiselanno et al., 2018). Selain ketiga strategi di atas, strategi nafkah sosial atau ikatan sosial merupakan strategi yang dapat meningkatkan ketahanan rumah tangga nelayan melalui ikatan sosial seperti kekerabatan, pertetanggaan serta pertemanan (Widodo, 2011). Strategi ikatan sosial mendukung saling pinjam permodalan dan hal lain untuk mendukung usaha nelayan. Rekayasa sumber nafkah nelayan di Kecamatan Limau ditampilkan pada Tabel 9. 
Tabel 9. Rekayasa sumber nafkah nelayan di Kecamatan Limau

\begin{tabular}{lccc}
\hline \multicolumn{1}{c}{ Rekayasa sumber nafkah } & Tidak Pernah $\mathbf{( \% )}$ & Sering $(\%)$ & Total \\
\hline Memiliki banyak sumber nafkah utama & 30 & 70 & 100 \\
Meminjam modal usaha & 78,75 & 21,25 & 100 \\
Memperluas lahan & 36,25 & 63,75 & 100 \\
Memperluas usaha & 27,50 & 72,50 & 100 \\
Menambah tenaga kerja & 88,75 & 11,25 & 100 \\
Menambah jam kerja & 7,5 & 92,50 & 100 \\
Menggunakan teknologi modern & 96,25 & 3,75 & 100 \\
\hline \multicolumn{1}{c}{ Rata-rata } & $\mathbf{5 2 , 1 4}$ & $\mathbf{4 7 , 8 6}$ & $\mathbf{1 0 0}$ \\
\hline
\end{tabular}

Sumber: Data Primer, 2020

Tabel 9 diperoleh gambaran bahwa sebanyak 70 persen nelayan memiliki banyak sumber nafkah, kemudian sangat sedikit nelayan yang meminjam modal usaha dari pihak lain ( 78,75 persen). Kemudian, sebanyak 88,75 persen nelayan tidak menambah tenaga kerja dengan pertimbangan keterbatasan biaya. Dari aspek teknologi, sebagian besar nelayan tidak menggunakannya ( 96,25 persen), umumnya nelayan menggunakan peralatan tangkap tradisional. Beberapa rekayasa sumber nafkah yang dilakukan nelayan di Limau adalah memperluas lahan pertanian, memperluas usaha baik disektor perikanan atau bukan, serta menambah jam kerja melaut untuk memperoleh hasil yang optimal.

\section{Pengarusutamaan Gender dalam Penyuluhan Perikanan}

Peranan perempuan dalam rumah tangga nelayan sangat besar dan tidak dapat diabaikan. Kemampanan ekonomi dan ketahanan rumah tangga nelayan sangat dipengaruhi oleh perempuan. Meskipun demikian, fenomena ketdaksetaraan gender khususnya sektor perikanan masih terjadi. Umumnya terdapat pandangan umum bahwa kedudukan perempuan hanya sebatas pada kegiatan domestik (mengurus rumah tangga). Perempuan dianggap lemah dan sedikit kontribusinya dalam aspek produktif (akses sumberdaya dan pekerjaan), begitu juga dalam aspek sosial umumnya hanya pihak laki-laki yang akan maju dalam kegitatan musyawarah, penyuluhan, pelatihan dan hal lainnya yang berkaitan dengan peningkatan kompetensi individu. Perempuan sangat lemah untuk mengakses hal tersebut.

Dalam aspek penyuluhan perikanan, banyak kegiatan yang tidak memberikan ruang secara langsung bagi kaum perempuan. Sehingga apabila perempuan terlibat dalam suatu pelatihan atau yang lainnya, biasanya perempuan akan menjadi minoritas dan sangat pasif karena didominasi oleh kaum pria. Kesenjangan gender disektor perikanan ditandai oleh masih rendahnya peluang yang dimiliki perempuan untuk bekerja dan berusaha. Selain itu, perempuan memiliki akses yang lemah terhadap sumberdaya ekonomi, teknologi informasi, pasar, dan lainnya. Hal tersebut dapat dilihat pada Tabel 5, poin kemasyarakatan. Oleh sebab itu, pembangunan sektor perikanan harus mengarusutamakan gender, perempuan harus diberi ruang lebih luas untuk meningkatkan partisipasi dan kepercaayaan dirinya. Kolaborasi terpadu antar stakeholder diperlukan dalam membangun kesetaraan gender dalam bidang perikanan khususnya di Kabupaten Tanggamus Provinsi Lampung.

\section{KESIMPULAN}

Secara akumulatif relasi gender keluarga nelayan di Kecamatan Limau mencakup kegiatan domestik, publik/produktif dan kemasyarakatan telah menunjukkan keterlibatan perempuan. Namun, umumnya perempuan hanya dominan dalam pekerjan domestik dan laki-laki dalam kegiatan produktif/publik dan kemasyarakatan. Nelayan di Kecamatan Limau menerapkan strategi nafkah ganda yang meliputi kolaborasi strategi On Farm, strategi On-Farm dan Off-Farm, serta strategi On-Farm dan Non-Farm. Sebagai upaya mendukung kesetaraan gender disektor perikanan khususnya penyuluhan, perlunya pengarusutamaan gender dalam penyusunan program penyuluhan yang memberikan peluang partisipasi kaum perempuan. Selain itu, perempuan harus memiliki akses yang lebih luas dari partisipasi, akses sumber daya keluarga, dan kontrol terhadap sumberdaya keluarga. 


\section{DAFTAR PUSTAKA}

Anggraini, Y. (2018). The Role of Women in Coastal Communities Improve Family Income of Fishermen in the Village of Bayah Sub District of Bayah Lebak Regency. Jurnal Kebijakan Pembangunan, 13(1), 97-106.

Ashari, B. H., Wibawa, B. M., \& Persada, S. F. (2017). Analisis Deskriptif dan Tabulasi Silang pada Surabaya. Jurnal Sains Dan Seni ITS, 6(2), 17-21.

Creswell, J. W. (2014). Research design Qualitative quantitative and mixed methods approaches. In Research design Qualitative quantitative and mixed methods approaches (Fourth). SAGE Publications. https://doi.org/10.3109/08941939.2012.723954

Damatun, M., Rantung, V. V, \& Memah, M. Y. (2017). Peran Tenaga Kerja Wanita Dalam Usahatani Hortikultura Di Kelurahan Wailan, Tomohon Utara, Kota Tomohon. Agri-Sosioekonomi, 13(1A), 169. https://doi.org/10.35791/agrsosek.13.1a.2017.15615

Damayanti, H. O. (2018). Strategi Pengembangan Usaha Penangkapan Ikan Tradisional (Studi Di Desa Pecangaan Kecamatan Batangan Kabupaten Pati). Jurnal Kebijakan Sosial Ekonomi Kelautan Dan Perikanan, 8(1), 13. https://doi.org/10.15578/jksekp.v8i1.6873

Delly, D. P., Prasmatiwi, F. E., \& Prayitno, R. T. (2019). Tingkat Ketahanan Pangan Rumah Tangga Nelayan Di Desa Sukajaya Lempasing Kecamatan Teluk Pandan Kabupaten Pesawaran. Jurnal Ilmu-Ilmu Agribisnis, 7(2), 141. https://doi.org/10.23960/jiia.v7i2.141-148

Fauziyah, E. (2018). Access and Control of Farm Households in the Management of Private Forest Resources. Jurnal Agroforestri Indonesia, 1(1), 33-45.

Fridayanti, N., \& Dharmawan, A. H. (2015). Analisis Struktur Dan Strategi Nafkah Rumahtangga Petani Sekitar Kawasan Hutan Konservasi Di Desa Cipeuteuy, Kabupaten Sukabumi. Sodality: Jurnal Sosiologi Pedesaan, 1(1), 26-36. https://doi.org/10.22500/sodality.v1i1.9388

Hamzah, A., Mukhtar, Abdi, \& Gafaruddin, A. (2019). Modernisasi alat tangkap pada nelayan Bajo: Sebuah studi pada nelayan suku Bajo di desa Latawe Kabupaten Muna Barat Provinsi Sulawesi Tenggara. Buletin Penelitian Sosial Ekonomi Pertanian Fakultas Pertanian Universitas Haluoleo, 21(1), 30-35.

Huberman, A., \& Miles, M. (2012). Understanding and Validity in Qualitative Research. In The Qualitative Researcher's Companion. https://doi.org/10.4135/9781412986274.n2

Hutajulu, J. (2014). Analisis peran perempuan dalam pertanian Di kecamatan rasau jaya kabupaten kuburaya. Jurnal Social Economic of Agriculture, 4(1), 83-90.

Imelda, I., Kusrini, N., \& Hidayat, R. (2019). Strategy of Sustainable Coastal Fisheries Management in Kubu Raya Regency Oleh : Marine Fisheries, 10(1), 59-69.

Istiana, I. (2014). Akses Perempuan Nelayan Dalam Kegiatan Produktif (Studi Kasus Di Desa Teluk, Kecamatan Labuan, Kabupaten Pandeglang, Banten). Buletin Ilmiah Marina Sosial Ekonomi Kelautan Dan Perikanan, 9(1), 1. https://doi.org/10.15578/marina.v9i1.205

Malik, T., Pattiselanno, A. E., \& Sopamena, J. F. (2018). Collaborative Strategy On Livelihoods Of Coastal Communities In Paperu Village Saparua District Central. Jurnal Agribisnis Kepulauan, 6(2), 141-154.

Munafi, L. O., \& Tenri, A. (2016). Strategi Adaptasi Nelayan Dan Perkembangan Modernisasi Perikanan Di Kota Baubau. Dimensi, 9(2), 73-78.

Mutolib, A., Yonariza, Mahdi, \& Ismono, H. (2016). Gender Inequality and the Oppression of Women within Minangkabau Matrilineal Society: A Case Study of the Management of Ulayat Forest Land in Nagari Bonjol, Dharmasraya District, West Sumatra Province, Indonesia. Asian Women, 32(3), 23-49.

Nimrah, S., Sakaria, S., Kunci, K., \& Budaya Patriarki, D. (2015). Perempuan Dan Budaya Patriarki Dalam Politik (Studi Kasus Kegagalan Caleg Perempuan Dalam Pemilu Legislative 2014 ). The 
POLITICS: Jurnal Magister Ilmu Politik Universitas Hasanuddin, 1(2), 2407-9138.

Nur, R. H., \& Najamuddin, N. (2020). Perubahan Pola Kehidupan Masyarakat Nelayan Desa Galesong Baru. Jurnal Pemikiran Pendidikan Dan Penelitian Kesejarahan, 7(2), 133-145.

Nurmayasari, I., Mutolib, A., Khoirunnisa, A., Hudoyo, A., Mangesti, R. A., \& Rahmadanti, R. (2020). Tingkat Kesetaraan Gender Pada Rumah Tangga Petani Sawi di Pekon Campang Kecamatan Gisting Kabupaten Tanggamus. JSHP : Jurnal Sosial Humaniora Dan Pendidikan, 4(1), 21-30. https://doi.org/10.32487/jshp.v4i1.783

Pattiselanno, A. E., Jambormias, E., \& Sopamena, J. F. (2018). Strategi Nafkah Petani Perkotaan Pulau Kecil (Studi Kasus Kecamatan Leitimur Selatan Kota Ambon). Jurnal Sosial Humaniora (, 11(2), 104-120.

Ridwan, M., Kasmi, M., \& Putri, A. R. S. (2019). Penentuan Komoditas Unggulan Perikanan Laut Kabupaten Polewali Mandar Berdasarkan Data Statistik Tahun 2016. Jurnal IPTEKS Pemanfaatan Sumberdaya Perikanan, 5(10), 98-105. https://doi.org/10.20956/jipsp.v5i10.6203

Sakina, A. I., \& Siti, D. H. A. (2017). Menyoroti Budaya Patriarki Di Indonesia. Share : Social Work Journal, 7(1), 71. https://doi.org/10.24198/share.v7i1.13820

Salatalohy, A. (2019). Strategi Dan Struktur Nafkah Rumahtangga Petani Agroforestri Kecamatan Parigi Kabupaten Gowa Propinsi Sulawesi Selatan. Jurnal Hutan Dan Masyarakat, 11(2), 126. https://doi.org/10.24259/jhm.v11i2.8297

Sembiring, S. T., \& Dharmawana, A. H. (2015). Resiliensi Nafkah Rumahtangga Petani Di Kawasan Rawan Bencana Rob Kecamatan Kampung Laut, Kabupaten Cilacap. Sodality: Jurnal Sosiologi Pedesaan, 2(1), 30-42. https://doi.org/10.22500/sodality.v2i1.9410

Syetiawan, A. (2015). Penentuan Zona Potensi Penangkapan Ikan Berdasarkan Sebaran Klorofil-a. Jurnal Ilmiah Geomatika, 21(2), 131-136.

Widodo, S. (2011). Strategi Nafkah Berkelanjutan bagi Rumah Tangga Miskin di Daerah Pesisir. Makara Sosial Humaniora, 15(1), 10-20.

Yanfika, H., Listiana, I., Mutolib, A., \& Rahmat, A. (2019). Linkages between Extension Institutions and Stakeholders in the Development of Sustainable Fisheries in Lampung Province. Journal of Physics: Conference Series, 1155(1), 1-6. https://doi.org/10.1088/1742-6596/1155/1/012014

Yanfika, H., Rangga, K. K., Viantimala, B., Listiana, I., Mutolib, A., \& Rahmat, A. (2020). Evaluation of the Success of Programs and Strategy for Sustainable Coastal Community Development in Tanggamus Regency. Journal of Physics: Conference Series, 1467(1). https://doi.org/10.1088/1742-6596/1467/1/012026

Yuliana, L., Widiono, S., \& Cahyadinata, I. (2016). Strategi Nafkah Rumah Tangga Nelayan Tradisional Dan Modern Pada Komunitas Nelayan Sekunyit, Kaur, Provinsi Bengkulu. Agrisep, 15(2 September), 163-175. https://ejournal.unib.ac.id/index.php/agrisep/article/view/1181

Yuliani, F. (2014). Ketidakadilan Gender dalam Pembangunan Pertanian: Studi Pandangan Politik Perempuan Anggota Legislatif di Kabupaten Kudus. Palastren, 7(2), 419-440. 